\title{
Variabilidade Isoesterásica Associada a Genes de Resistência à Ferrugem da Folha do Trigo*
}

\author{
Cheila C. Sbalcheiro' ${ }^{1}$, Sandra P. Brammer ${ }^{2}$ \& Amarilis L. Barcellos ${ }^{3}$ \\ ${ }^{1}$ Universidade de Passo Fundo, Mestrado em Agronomia, Passo Fundo, RS, e-mail: cheilacris@ @otmail.com; ${ }^{2}$ Embrapa \\ Trigo, Rodovia BR 285, Km 174, Cx. Postal 451, CEP 99001-970, Passo Fundo, RS, e-mail: sandra@ cnpt.embrapa.br; \\ ${ }^{3}$ OR Melhoramento de Sementes Ltda, Rua João Battisti, 71, CEP 99050-380, Passo Fundo, RS
}

(Aceito para publicação em 17/03/2005)

Autor para correspondência: Sandra P. Brammer

SBALCHEIRO, C.C., BRAMMER, S.P. \& BARCELLOS, A.L. Variabilidade isoesterásica associada a genes de resistência à ferrugem da folha do trigo. Fitopatologia Brasileira 30:267-273. 2005.

\section{RESUMO}

A triticultura brasileira apresenta constantes perdas no rendimento, associadas à ocorrência da ferrugem da folha, causada pelo fungo Puccinia triticina. A incorporação da resistência genética e o conhecimento do número de genes envolvidos são importantes para os programas de melhoramento genético vegetal, que a cada ano têm introduzido resistência qualitativa nas cultivares, visando superar o aparecimento de novas raças do patógeno. As técnicas bioquímicas, baseadas na análise de polimorfismo de enzimas, possibilitam a rápida e precisa detecção de marcadores moleculares, para o estudo de aspectos básicos de genética vegetal, bem como representam valiosa ferramenta de apoio aos programas de melhoramento, pois permitem a identificação antecipada de genótipos resistentes e suscetíveis. Este trabalho visa avaliar, fitopatológica e molecularmente, a população haplodiplóide Trigo BR 35 (resistente)/IAC 13-Lorena (suscetível) de trigo (Triticum aestivum), quanto à resistência de planta adulta à ferrugem da folha, bem como à similaridade genética presente na progênie haplodiploidizada na geração $F_{1}$. Nas avaliações fitopatológicas em planta adulta, das 96 linhas duplo-haplóide, 29 foram resistentes, 15 suscetíveis e 52 intermediárias apresentaram reação que variou entre nível de resistência inferior ao determinado para Trigo BR 35 a menos suscetível do que IAC 13-Lorena. A análise genética revelou dois genes parcialmente dominantes. $\mathrm{Na}$ análise bioquímica, através do sistema isoenzimático das esterases, foram detectadas, seis bandas, todas anódicas e com especificidade alfa-esterásica, cujas MRs (migração relativa) variaram de 0,09 a 0,69. Quanto à variabilidade genética, foi detectada, para as 96 linhas, elevada similaridade genética, a qual confirmou as análises isoesterásicas.

Palavras-chave adicionais: Triticum aestivum, Puccinia triticina, esterase, similaridade genética.

\begin{abstract}
Isoesterase variability associated with gene resistant wheat leaf rust

Yield redutions associated with leaf rust, caused by the fungus Puccinia triticina, are recorded for Brazilian wheat (Triticum aestivum) crops. Incorporation of genetic resistance and knowing the number of genes involved are important tools for plant genetic breeding programs, which are consistently introducing qualitative resistance in cultivars aiming to cope with new races of the pathogen. Biochemical techniques, based upon the analysis of the polymorphism of enzymes, provide a rapid and accurate detection of molecular markers and, also, play a valuable support role in breeding programs for predicting the identification of resistant and susceptible genotypes. The objective of this investigation was to carry out a phytopathological and molecular assessment of the haplodiploid population Trigo BR 35 (resistant)/IAC13-Lorena (susceptible) as to its adult plant resistance to leaf rust, as well as to the genetic similarity available in the progeny haplodiploidized in $\mathrm{F}_{1}$ generation. From a total of 96 double haploid lines evaluated for leaf rust, at adult-plant stage, 29 were resistant, 15 were susceptible and 52 showed less resistance than Trigo BR 35 than that presented by IAC 13-Lorena. The genetic analysis showed that the resistance was due to two partially dominant genes. In the biochemical analysis, made through isoenzymatic esterase system, six bands were detected, all of them anodic and with alpha-esterasic specificity the relative migration varied from 0,09 to 0,69 .
\end{abstract} A high genetic similarity was detected, which confirmed isoesterasic analyses, for the 96 double haploid lines.

Additional keywords: Triticum aestivum, Puccinia triticina, esterase, genetic similarity.

\section{INTRODUÇÃO}

A triticultura apresenta perdas no rendimento, devido à ocorrência da ferrugem da folha do trigo (Triticum aestivum L.), causada pelo fungo Puccinia triticina Erikss,

*Trabalho de conclusão de Iniciação à Pesquisa do Curso de Ciências Biológicas do primeiro autor. Universidade de Passo Fundo (2003). anteriormente descrita como Puccinia recondita Roberge. ex Desmaz. f. sp. tritici (Anikster et al., 1997). Esta merece destaque por ser uma das doenças fúngicas mais comuns e prejudiciais à cultura. As áreas tritícolas brasileiras constituem um ambiente favorável ao desenvolvimento do fungo, além da infecção servir como "porta de entrada" para outras doenças oportunistas (Brammer, 2000). 
O início da ocorrência e a intensidade da doença podem determinar a produtividade e influenciar economicamente no produto. Diante deste fato, a resistência genética é o método mais eficiente e econômico de controle do patógeno, uma vez que novas raças virulentas de $P$. triticina superam a resistência da planta à ferrugem da folha (Barcellos, 1994; Humphreys et al., 2003).

Ardiel et al. (2002) destacam que a compreensão sobre o modo de herança da resistência é valiosa para o planejamento dos cruzamentos num programa de melhoramento genético, na identificação de genes de resistência e no desenvolvimento de marcadores genéticos para uso em seleção assistida.

No melhoramento genético, o uso de marcadores morfológicos nem sempre é eficiente, pois variam conforme as condições ambientais. Entretanto, técnicas bioquímicas e moleculares baseadas na análise de polimorfismo de enzimas e de fragmentos de DNA possibilitam a rápida detecção de marcadores genéticos no estudo de aspectos básicos de genética vegetal, sendo também uma ferramenta de apoio aos programas de melhoramento, pois possibilitam de forma mais rápida e precisa a avaliação e a identificação antecipada de genótipos resistentes e suscetíveis, antes que a doença incida sobre a cultura do trigo (Brammer, 2000).

Os marcadores genéticos, bioquímicos e moleculares, além de serem identificáveis em qualquer idade da planta, não interferem com o processo biológico que se deseja estudar (Robinson, 1998). Dentre os diversos tipos, merecem destaque as isoenzimas por serem controladas geneticamente por um ou vários genes, situados num mesmo loco ou em diferentes locos, respectivamente. Numerosos estudos de locos enzimáticos revelam a existência de níveis expressivos da variação genética intra e interpopulacional em uma mesma espécie, além da diferenciação considerável entre espécies no grau de heterogeneidade isoenzimática intrapopulacional (Brammer et al., 2002).

O uso de isoenzimas no estudo de estresse biótico ou abiótico está relacionado ao entendimento das mudanças metabólicas e mecanismos de defesa que ocorrem em plantas (Burdon \& Marshall, 1983), aliados ao fato que os polimorfismos enzimáticos estão mais perto da expressão fenotípica final do que os polimorfismos de DNA, por serem um produto intermediário da expressão do gene (Torggler et al., 1995).

Neste contexto, Bocchese et al. (2003), em revisão sobre o uso de isoenzimas e proteínas para a identificação e caracterização da virulência de fitopatógenos, citam diversos pesquisadores que usaram e ainda vêm usando tal metodologia com eficiência, rapidez e baixo custo. Dentre as comumente utilizadas, destacam as esterases, por ser um dos sistemas isoenzimáticos mais polimórficos, e por estar relacionada com a patogenicidade.

Com relação ao emprego das isoenzimas em trigo associadas à ferrugem da folha, alguns trabalhos são citados: Narasimham \& Chawla (1989) analisaram a expressão da enzima polifenol oxidase estando ligada ao gene $\operatorname{Lr} 19$; McMillin et al. (1993) relatam que a isoenzima endopeptidase também se apresenta ligada ao gene Lr19; Wang et al. (1994) estudaram mudanças na atividade das peroxidases, associadas aos genes $L r$, durante as infecções de $P$. recondita; Brammer et al. (2002) identificaram, um marcador isoesterásico associado ao gene Lr24; Kraic et al. (2003) realizaram seleção assistida via marcador isoenzimático ligado ao gene Ep-D1c e marcadores de DNA na detecção da incorporação dos genes $L r 19+L r 24$ em cultivares comerciais de trigo.

Este trabalho visou avaliar fitopatológica e molecularmente a população haplodiplóide Trigo BR 35/IAC 13-Lorena, quanto à resistência de planta adulta à ferrugem da folha, bem como a similaridade genética intrapopulacional, presente na progênie.

\section{MATERIAL E MÉTODOS}

O trabalho foi realizado no laboratório de Biotecnologia Vegetal e casa de vegetação da Embrapa Trigo, Passo FundoRS. Foram avaliadas 96 linhas duplo-haplóides oriundas do cruzamento en tre as cultivares Trigo BR 35 (resistente) e IAC 13-Lorena (suscetível). A escolha do parental resistente deveu-se ao fato deste apresentar resistência de planta adulta e por manter esta condição na lavoura, por mais de 12 anos. Quanto ao inóculo, testes iniciais foram realizados, a fim de verificar aquele que apresentasse virulência em plântula (primeira folha), para as duas cultivares, e avirulenta em planta adulta à cultivar Trigo BR 35. O inóculo utilizado, segundo o Sistema Norte Americano de Nomenclatura (Long \& Kolmer, 1989) foi o MFT-HS (genes efetivos para resistência: $L r$ 2a, 2c, 9, 10, 16, 20, 21/genes não efetivos: $L r$ 1, 3, 3ka, 11, 14a, 14b, 17,18, 23, 24, 26, 30.

\section{Inoculação de Puccinia triticina e análise da resistência}

Para a aplicação do inóculo, foram usados $1,5 \mathrm{mg} / \mathrm{ml}$ de esporos, diluídos em óleo Soltrol. O inóculo foi aplicado nas folhas, com auxílio de um aparelho de ar comprimido, seguido, após secar o óleo, da aspersão de água com Tween $20 \%$, a fim de permanecer uma camada de água sobre as mesmas, antes do ponto de escorrimento. O material foi deixado na incubação e no escuro por, aproximadamente, $30 \mathrm{~h}$, a $20{ }^{\circ} \mathrm{C}$, sob umidade não inferior a $90 \%$. Após a inoculação, as plantas foram mantidas, em câmaras de crescimento, em condições de luz $(12 \mathrm{~h} /$ dia $)$ e temperatura $\left(20^{\circ} \mathrm{C}\right)$ adequadas para o desenvolvimento da ferrugem.

As avaliações fitopatológicas foram feitas nos genitores, plantas $F_{1}$ e nas linhas duplo-haplóides, 15 dias após a inoculação com P. triticina. Para a fase de planta adulta, foi usada a escala segundo Roelfs et al. (1992), na qual foi avaliada a folha bandeira do perfilho principal, analisandose o tamanho e a percentagem de pústulas presentes nas folhas infetadas, observando-se também a ocorrência de cloroses e necroses foliares. A partir destas avaliações, fez-se a análise genética quanto ao número de genes envolvidos na resistência. Para tal, o método empregado foi do qui-quadrado.

\section{Eletroforese de isoenzimas}

Para a análise de isoenzimas foram usadas as mesmas 
sementes das análises fitopatológicas, com três repetições. O sistema das esterases (EST), EC 3.1.1 foi analisado por eletroforese, na fase de plântula. Quando esta media cerca de $10 \mathrm{~cm}$ de comprimento, foi coletado cerca de $2 \mathrm{~cm}$ da parte apical. A metodologia usada para o preparo de soluções tampão das amostras e da eletroforese, bem como dos géis e a revelação dos mesmos, foi a descrita por Scandalios (1969). A distância entre a ponte catódica e anódica foi sempre de $12,0 \mathrm{~cm}$ e a intensidade de campo de $10 \mathrm{~V} / \mathrm{cm}$. Em seguida, os géis foram lavados em água corrente e fixados com solução contendo $450 \mathrm{ml}$ de álcool metílico, $110 \mathrm{ml}$ de ácido acético e $440 \mathrm{ml}$ de água destilada, por cerca de $20 \mathrm{~min}$.

As análises das isoesterases foram baseadas na representação da migração absoluta (MA) em papel milimetrado, sendo anotadas as distâncias migradas pelas bandas a partir do ponto de aplicação, em centímetros, com precisão de 0,5 $\mathrm{mm}$, bem como a intensidade de coloração de cada banda. A partir desse esquema, foi calculada a migração relativa (MR) de cada banda, em relação à da linha de frente, que recebeu o valor relativo igual a 1,00. A MR indica a relação entre a distância migrada pela banda em questão e a distância migrada pela linha de frente. Bandas de difícil visualização foram desconsideradas. Para cada MR, foi calculada a freqüência alélica.

As análises estatísticas, quanto à similaridade genética foram realizadas através do programa NTSYS pc 2.0 (Rohlf, 1998). A similaridade genética foi estimada pelo coeficiente de Jaccard, sendo que as plantas foram agrupadas baseadas na matriz de similaridade genética usando o UPGMA, ou método de agrupamento aos pares usando médias não ponderadas, sendo que as plantas foram consideradas as unidades taxonômicas operacionais (OTUs) e os caracteres (binários) foram as bandas isoenzimáticas.

\section{RESULTADOS E DISCUSSÃO}

Os resultados obtidos neste trabalho, com as avaliações fitopatológicas, revelaram que a raça escolhida de P. triticina possibilitou a adequada avaliação, bem como a caraterização do material analisado para uso nas análises genéticas. $\mathrm{Na}$ fase de planta adulta, foram avaliadas 96 plantas para o inóculo MFT-HS, as quais 29 foram resistentes e 15 suscetíveis, com reação similar a Trigo BR 35 e IAC 13Lorena, respectivamente. As demais 52 plantas apresentaram reação em níveis diferenciados, desde resistência inferior a do Trigo BR 35 a menos suscetibilidade do que IAC 13Lorena.

Barcellos (1994) enfatiza que nos estudos genéticos, é muito importante usar raças com combinações conhecidas de avirulência e de virulência. As pesquisas genéticas devem ser efetuadas com raças puras para evitar qualquer confusão ao se avaliarem as reações de infecção. Do mesmo modo, nos estudos genéticos a campo, utiliza-se uma só raça, se possível.

Em relação à análise genética, foi detectada a presença de dois genes no Trigo BR 35 para a resistência à ferrugem da folha, os quais foram expressos na fase de planta adulta, sendo que os valores obtidos das avaliações fitopatológicas foram usados para este tipo de análise. Primeiramente, foram testadas várias hipóteses de segregação genética, aliados ao fato de que já se sabia, a partir da literatura consultada, que são poucos o número de genes envolvidos neste tipo de herança. Portanto, o valor do teste do qui-quadrado $\left(\chi^{2}=4,745\right)$, foi não significativo ao nível de $0,05 \%$ de probabilidade e dois graus de liberdade, considerando-se para a raça testada a hipótese de dois genes parcialmente dominantes. A dominância parcial foi também indicada pela reação das plantas na geração $\mathrm{F}_{1}$. Estes resultados, quanto à herança ser oligogênica, corroboram com os estudos realizados por Dyck et al. (1966); Bartos et al. (1969); Lee \& Shaner (1985); Barcellos (1994) e Brammer (2004), entre outros.

Para as análises qualitativas e quantitativas das isoesterases as plantas duplo-haplóide, que apresentaram um padrão de bandas idêntico, foram agrupadas em um mesmo zimograma. Quando plantas-irmãs apresentaram padrões diferentes seja por variações qualitativas e quantitativas esses padrões foram individualizados. Foram detectadas, no total, seis bandas anódicas e com especificidade alfa-esterásica, cujas MRs variaram de 0,09 a 0,69. A variação qualitativa foi medida pela intensidade da banda, variando de muito fraca, fraca, média e forte, sendo que a mais freqüente foi a de intensidade muito fraca. Para a MR 0,30, esta se apresentou com as quatro intensidades e freqüência alélica de 1,00 , ocorrendo em todas as 273 plântulas avaliadas, incluindo as três repetições. Por sua vez, a MR 0,55 teve a menor freqüência alélica $(0,013)$, sendo detectada em apenas quatro plântulas (Figura 1). De modo geral, poucas diferenças quantitativas foram observadas para todas as amostras analisadas, indicando um baixo nível de variabilidade intrapopulacional.

Kephart (1990) aborda que das 26 enzimas comumente analisadas em plantas, o número de locos varia de um a dois por sistema enzimático, com exceção das esterases que variam de dois a dez locos. Pascholati et al. (1993) relatam que um dos sistemas comumente utilizados é o de esterase, já que a mesma está relacionada com a patogenicidade, além de ser polimórfica e de fácil detecção.

No presente trabalho, cuja população segregante seja oriunda de pais bem contrastantes quanto à resistência e suscetibilidade à ferrugem da folha e, embora tenha sido proposto verificar uma possível relação entre as avaliações fitopatológicas com às moleculares, não foi detectada nenhuma banda isoenzimática específica. Estudos posteriores deverão ser conduzidos por meio de outros marcadores, tanto bioquímicos como moleculares, a fim de permitir tal associação e possibilitar o desenvolvimento de marcadores genéticos para uso em seleção assistida.

Análises de isoesterases realizados por Bochese et al. (2003), em oito isolados de Pyrenophora chaetomioides Speg., agente causal da mancha foliar e do grão de aveia, também não permitiram estabelecer uma associação entre o padrão obtido para as alfa e beta esterases e virulência dos isolados. Contudo, tais autores detectaram elevada variabilidade entre 


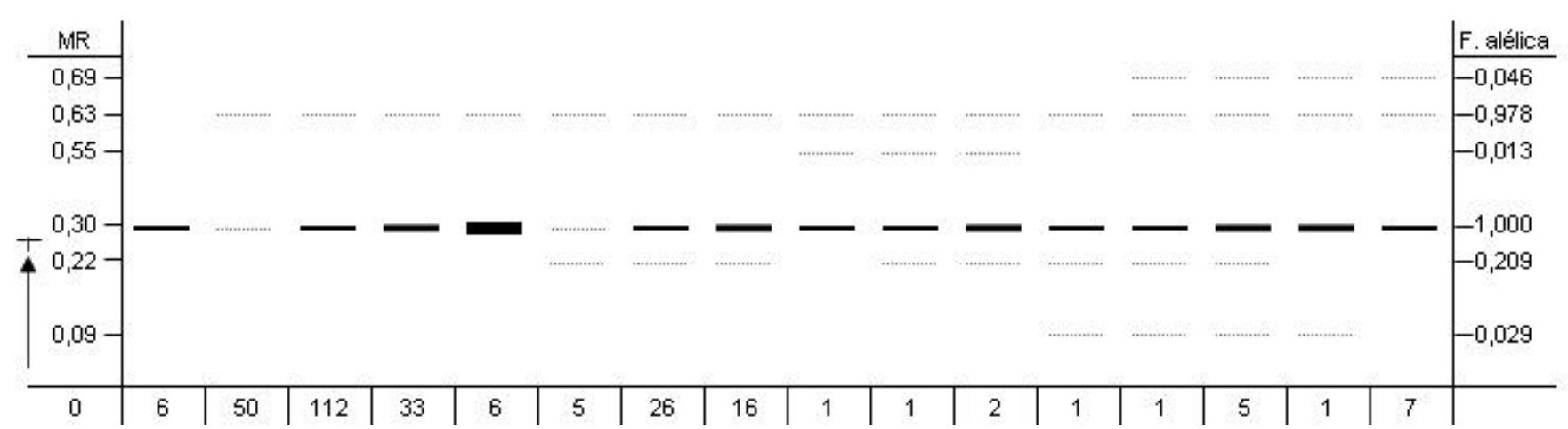

FIG. 1 - Zimograma representando as seis bandas isoesterásicas de genótipos de trigo (Triticum aestivum) com suas respectivas MRs (Migração Relativa), que apresentam, conforme o padrão de bandas e a sua frequiência alélica.

Onde: $\quad$ …….... Muito Fraca, — Fraca, Média, — Forte.

os isolados estudados, sendo que os mesmos apresentaram sete perfis distintos.

Elevada similaridade também é detectada para grandes espécies vegetais. Zheng et al. (2001) avaliaram a variação genética, por meio das técnicas das esterases, gliadinas e marcadores de DNA, em 40 cultivares comerciais de trigo chineses cultivados na maior região tritícola da China. Para as esterases, foram detectados somente sete padrões isoesterásicos entre todos os materiais analisados, sendo que destes, $80 \%$ tiveram padrões idênticos.

Esse grande número de isoenzimas, detectadas em plantas, pode ser devido à duplicação gênica, em espécies diplóides, ou a adição de genomas em espécies poliplóides (Gottlieb, 1982). De modo semelhante, a variação em certas isoenzimas pode ser importante na capacidade das plantas sobreviverem em uma variedade de ambientes. Assim, certos fatores que afetam o metabolismo da planta como nutrição, temperatura e infecções por patógenos, influenciam a intensidade da atividade enzimática e podem induzir o surgimento de formas moleculares múltiplas, por ativação de genes.

Recentemente, Brammer et al. (2002), em trabalho realizado com linhas isogênicas de trigo, portadoras de resistência de plântula à ferrugem da folha, observaram a presença de nove bandas isoesterásicas, sendo a mais anódica, a beta-esterásica, com migração relativa de 0,61. As demais, como sendo alfa-esterásicas, apresentaram variação de MRs de 0,55 e 0,06. Foi verificado que não ocorreu nenhuma diferenciação quantitativa e qualitativa nos padrões isoesterásicos para os genes $\operatorname{Lr} 9, \operatorname{Lr} 16, \operatorname{Lr} 19$ e $\operatorname{Lr} 26$. Já o padrão detectado para o gene Lr24 mostrou polimorfismo, caracterizando a banda de MR 0,20 como um marcador para esse sistema.

A baixa variabilidade genética detectada para a população Trigo BR35/IAC 13-Lorena, no presente trabalho, pode ser explicada, entre outros fatores, por Parker \& Hamrick (1992), que em revisão sobre sistemas de reprodução das plantas, abordam que as espécies com reprodução predominantemente assexual mantêm os mesmos níveis de diversidade que as espécies com reprodução sexual, embora a maior variabilidade genética intrapopulacional ser encontrada em espécies de fecundação cruzada do que de autofecundação. Embora o trigo de panificação seja considerado, ainda, como uma espécie de ampla base genética, por apresentar três genomas distintos, vem sofrendo a pressão de seleção exercida pelos melhoristas, o que contribui para uma significativa redução na variabilidade genética. Genes localizados em genomas distintos possuem o poder de neutralizar a expressão e manifestação de outros genes, dificultando o ganho genético através de seleção (Bered et al., 2000).

Portanto, a variabilidade genética das populações é uma consequiência do tipo de sistema de reprodução das mesmas, ou seja, plantas alógamas possuem maior heterogeneidade interna do que as autógamas. Além disso, Jain (1976) cita uma série de conseqüências com relação ao sistema de autofecundação, das quais pode-se destacar: o aumento da homozigose, menor número de locos polimórficos e alelos, restrição da recombinação, o aumento de associações multilocos, a economia reprodutiva, entre outros.

Em relação à elevada similaridade genética, detectada na progênie oriunda de Trigo BR35/IAC 13-Lorena, foram formados seis grupos, a partir da maior similaridade para a de menor similaridade, coeficiente de Jaccard $=1,00$ e 0,44, respectivamente. $\mathrm{O}$ grupo $\mathrm{A}$, formado de 15 linhas duplohaplóides, diferenciou-se do grupo B com duas linhas, que se diferenciaram do grupo $\mathrm{C}$ composto de 72 linhas e do grupo $\mathrm{D}$ com três linhas, tendo todas as linhas destes grupos com similaridade de $100 \%$. Estes por sua vez diferenciaram-se dos grupos E e F, com duas linhas cada, apresentando menor similaridade conforme o dendrograma (Figura 2). Esses resultados estão de acordo com o esperado, visto que a população foi haplodiploidizada na geração $\mathrm{F}_{1}$, são poucos os genes de resistência e o trigo é uma espécie autógama.

Devido ao fato da haploidiploidização originar plantas completamente homozigotas, oriundas dos gametas masculino ou feminino, que representam diretamente a segregação gamética após a meiose, esta técnica representa uma poderosa ferramenta tecnológica, principalmente nas culturas autógamas.

Ao se eliminar o mascaramento causado pela 


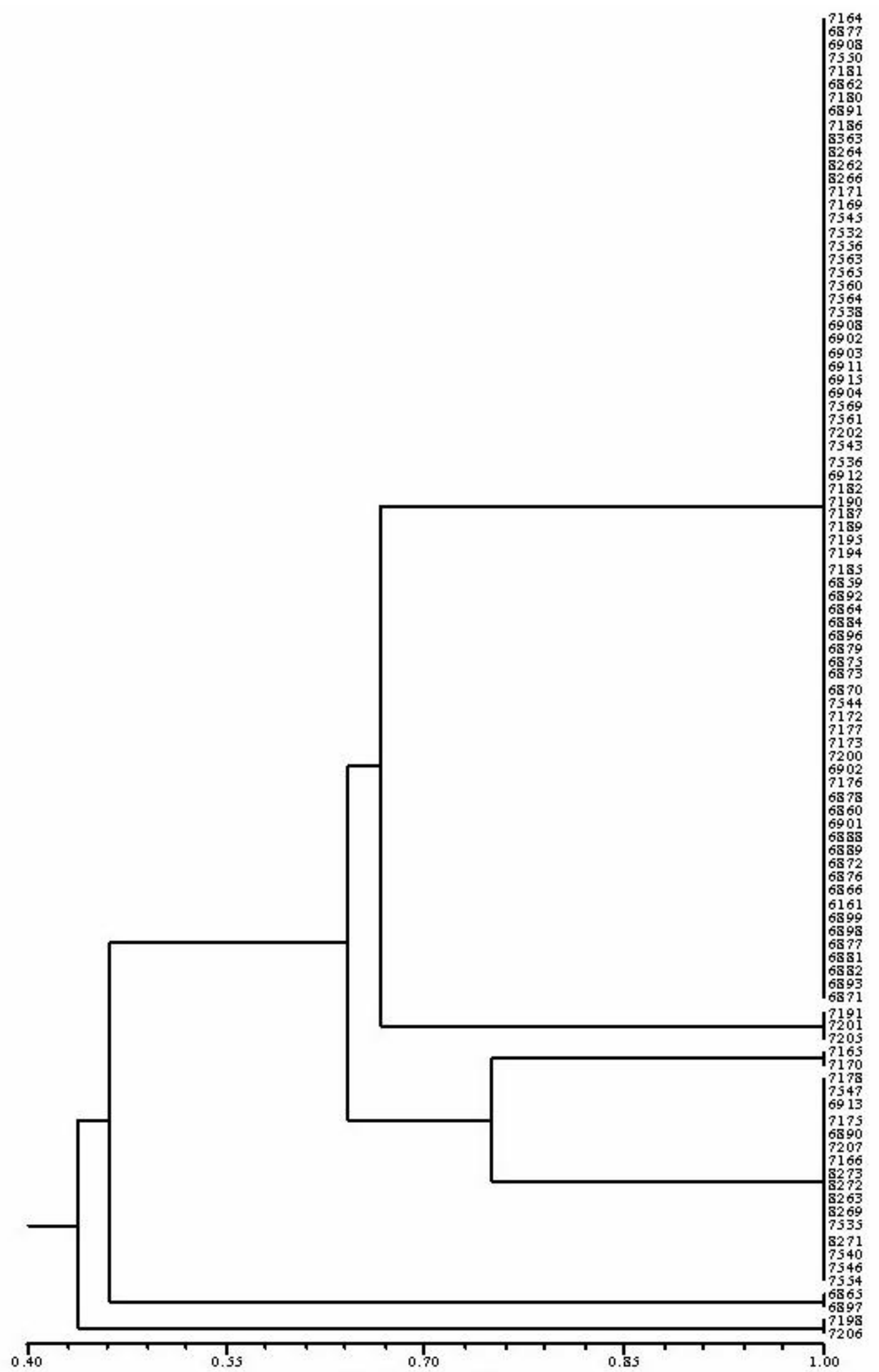

FIG. 2 - Dendrograma de similaridade genética da população de linhas duplo-haplóides de trigo (Triticum aestivum) ('BR 35' x 'IAC 13-Lorena'), estimadas pelo coeficiente de Jaccard. 
heterozigose, soluciona-se uma das principais limitações dos métodos clássicos de melhoramento, ou seja, a dificuldade e a aleatoriedade da seleção nas populações $F_{2}$ (Demarly, 1977). Como consequiência da eliminação das gerações segregantes heterozigotas é possível o lançamento antecipado de novas cultivares; maior precisão na seleção por causa de ausência da heterozigose; maior ganho genético para caracteres com herança aditiva e grande simplificação na análise genética quantitativa (Brammer et al., 2002).

Clegg et al. (1972) enfocam que complexas relações existem entre seleção, ligação, tamanho efetivo da população e sistema de cruzamento, quando dois ou mais locos são considerados e segregam simultaneamente. População de plantas predominantemente auto-polinizadas são favoráveis para tais estudos, devido ao intenso endocruzamento que ocorre nessas populações, sendo que o esperado é resultar numa drástica restrição de recombinação entre locos.

\section{REFERÊNCIAS BIBLIOGRÁFICAS}

ANIKSTER, Y., BUSHNELL, W.R., EILAM, T., MANISTERSKI, J. \& ROELFS, A.P. Puccinia recondita causing leaf rust on cultivated wheats, wild wheats, and rye. Canadian Journal of Botany 75:20822096. 1997.

ARDIEL, G.S., GREWAL T.S., DEBERDT P., ROSSNAGEL, B.G. \& SCOLES G.J. Inheritance of resistance to covered smut in barley and development of a tightly linked SCAR marker. Theoretical and Applied Genetics 104:457-464. 2002.

BARCELLOS, A.L. Genética da resistência de planta adulta à ferrugem da folha na cultivar brasileira de trigo Toropi (Triticum aestivum L. em Thell). (Tese de Doutorado). Porto Alegre. Universidade Federal do Rio Grande do Sul. 1994.

BARTOS, P., DYCK, P.L. \& SAMBORSKI, D.J. Adult-plant leaf rust resistance in Thatcher and Marquis wheat: a genetic analysis of the host-parasite interaction. Canadian Journal of Botany 47:267269. 1969.

BERED, F., CARVALHO, F.I.F. de \& BARBOSA NETO, J.F. Variabilidade genética em trigo. Biotecnologia Ciência e Desenvolvimento 14:22-25. 2000.

BOCCHESE, C.A.C., MARTINELLI, J.A., MATSUMURA, T.S., FEDERIZZI, L.C. \& PRESTES, A.M. Virulência, atividade enzimática e padrões de isosterases de isolados de Pyrenophora chaetomioides, agente etiológico da mancha de grãos e folhas de aveia. Fitopatologia Brasileira 28:11-16. 2003.

BRAMMER, S.P. Mapeamento de genes de resistência parcial à ferrugem da folha do trigo em cultivares brasileiras de trigo (Triticum aestivum L. em Thell). (Tese de doutorado). Porto Alegre. Universidade Federal do Rio Grande do Sul. 2000.

BRAMMER, S.P., SALAZAR, S., MORAES-FERNANDES, M.I.B. \& BARCELLOS, A.L. Identificação de marcadores isoesterásico associado ao gene $L r 24$ com resistência à ferrugem da folha em trigo. Passo Fundo: Embrapa Trigo, 2002. 12 p. html. (Embrapa Trigo. Circular Técnica Online; 13). Disponível: http:// www.cnpt.embrapa.br/biblio/p_ci13.htm

BRAMMER, S.P., MORAES-FERNANDES, M.I.B., BARCELLOS, A.L. \& MILACH, S.C.K. Genetic analysis of adultplant resistance to leaf rust in a double haploid wheat (Triticum aestivum L. em Thell) population. Genetics and Molecular Biology 27:432-436. 2004.

BURDON, J.J.\& MARSHALL, D.R. The use of isozymes research. In: Tanksley, S.D. \& Orton, T.J. (Eds). Isosymes in plants genetics and breeding: Part A. Amsterdam: Elsevier. 1983. pp.401-412.

CLEGG, M.T., ALLARD, R.W. \& KAHLER, A.L. Is the gene unit of selection? Evidence from two experimental plant populations. Proceeding of the National Academy Sciences 69:2474-2478. 1972.

DEMARLY, Y. Génétique et amélioration des plantes. Paris: Masson. Collection Sciences Agronomiques. 1977.

DYCK, P. L., SAMBORSKY, D. J. \& ANDERSON, L. G. Inheritance of adult plant leaf rust resistance derived from the common wheat varieties exsange and Frontana. Canadian Journal of Genetics and Cytology 8:665-671. 1966.

GOTTLIEB, L.D. Conservation and duplications of isozymes in plants. Science 216:373-380. 1982.

HUMPHREYS, G., McCALLUM, B., LUKOW, O.M., DEPAUW, R. \& HIEBERT, C. Evaluation of "Tatcher" iso-lines containing new sources of leaf rust resistance as potential " $L r$ " donors for wheat breeding programs. Proceedings of the Tenth International Wheat Genetics Symposium 2:724-726. 2003.

JAIN, S.K. The evolution of inbreeding in plants. Annual Review of Ecology Systematics 7:469-495. 1976.

KRAIC, J., SLIKOVÁ, S., HUdCOVICOVÁ, M., GREGOVÁ, E. \& BARTOS, P. Leaf rust resistant wheat lines developed by marker assisted selection. Proceedings of the Tenth International Wheat Genetics Symposium 2:739-741. 2003.

KEPHART, S. R. Starch gel electrophoresis of plant isozymes: a comparative analysis of techniques. American Journal of Botany 77:693-712. 1990.

LEE, T.S. \& SHANER, G. Oligogenic inheritance of length of latente period in six slow leaf-rusting wheat cultivars. Phytopathology 75:636-643. 1985.

LONG, D.L. \& KOLMER, J.A. A North American system of nomenclature for Puccinia recondita f. sp. tritici. Phytopathology 79:525-529. 1989.

McMILLIN, D.E., JOHNSON, J.W. \& ROBERTS, J.J. Linkage between endopeptidase Ep. D1d and gene confering leaf rust resistance ( $\operatorname{rr} 19)$ in wheat. Crop Science 33:1201-1203. 1993.

NARASIMHAM, J.V. \& CHAWLA, H.S. Polyphenol oxidase enzyme in isogenic lines of wheat in relation to leaf rust resistance. Wheat Information Service 69:18-20. 1989.

PARKER, K.C. \& HAMRICK, J.L. Genetic diversity and clonal structure in a colummar cactus, Lophocereus schotti. American Journal of Botany 79:86-96. 1992.

PASCHOLATI, S.F., DEISING, H., LEITE, B., ANDERSON, D. \& NICHOLSON, R.L. Cutinase e non-specific esterase activities in the conidial mucilage of Colletotrichum graminicola. Physiological and Molecular Plant Pathology 42:37-51. 1993.

ROBINSON, I.P. Aloenzimas na genética de populações de plantas. In: Alfenas, A.C. (Ed.). Eletroforese de isoenzimas e proteínas afins - fundamentos e aplicações em plantas e microrganismos. Editora da Universidade Federal de Viçosa. 1998. pp.329-367.

ROELFS, A.P., SINGH, R.P. \& SAARI, E.E. Las Royas Del Trigo: Conceptos y métodos para el manejo de esas enfermidades. México, D.F.: CIMMYT. 1992. 
ROHLF, J.F. NTSYS-pc. Numerical Taxonomy and Multivariate Analysis System. Versão 2.0. University New York. Applied Biostatistics Inc. 1998.

SCANDALIOS, J.G. Genetic control of multiple forms of enzymes in plants: a review. Biochemical Genetics 3:37-79. 1969.

TORGGLER, M.G.F., CONTEL, E.P.B. \& TORGGLER, S.P. Isoenzimas - variabilidade genética em plantas. Ribeirão Preto: Sociedade Brasileira de Genética. 1995.
ZHENG, Y.L., CHEN, Y.Q., WEI, Y.M., ZHOU, Y.H., ZHANG, Z.Q., LIU, D.C., LAN, X.J. \& YAN, Z.H. Esterase, gliadins and RAPD variations among Sichuan wheat cultivars. Wheat Information Service 92:5-8. 2001.

WANG, D.M., WANG, Z.X., YANG, X.P., LIU, J. \& HAN, G.S. Changes of peroxidase acitivity and isozyme in the course of leaf rust infection of wheat lines with $L r$ gene. Journal of Hebei Agricultural University 17:1-6. 1994. 